\title{
Dosslê
}

\section{O sentido do conceito humanizador no trabalho de tutores a distância}

\author{
Creuza Martins França ${ }^{1}$ \\ Adriana Martini Tavano Silva ${ }^{2}$ \\ Alessandra Dutra ${ }^{3}$ \\ DaVid da Silva Pereira ${ }^{4}$ \\ JAIR DE OLIVEIRA ${ }^{5}$
}

Resumo: Este estudo busca apresentar o perfil de dez tutores de uma instituição de ensino superior particular da cidade de Londrina-PR, bem como apresentar as percepções desses tutores sobre sua formação inicial no que se refere ao uso de tecnologias, identificar se esses profissionais sentem-se preparados para mediar a aprendizagem em Ambiente Virtual de Ensino e Aprendizagem (AVEA), conhecer a percepção desses tutores sobre a ambientação recebida na instituição ao iniciar suas atividades no ensino a distância, verificar as dificuldades encontradas durante a mediação pedagógica, conhecer como os tutores realizam a acolhida do aluno a distância e, por fim, analisar se as ações dos tutores contemplam uma perspectiva de educação humanizada. Tal temática é relevante, uma vez que o papel desempenhado pelo tutor revela-se enquanto facilitador do processo de ensino-aprendizagem. Foram trazidas à tona algumas reflexões a partir do aporte teórico de Belloni (2012), Moran (2015) e Gasparoni (2017). Na abordagem metodológica, optou-se pelas contribuições de Severino (2007). Contou-se ainda com a análise das interpretações dos dados segundo a perspectiva de Rodrigues, Schimidt e Marinho (2011) e Tenório, Souto e Tenório (2014). Os resultados mostraram que os pesquisados possuem capacidade em direcionar suas práticas por meio de ações de acolhida e incentivo, o que corrobora a percepção dos referenciais sobre a tutoria humanizada.

Palavras-chave: Tecnologia. Educação a distância. Formação de tutores humanizadores.

\section{The meaning of the humanizing concept in the work of distance tutors}

\begin{abstract}
This study aims to present the profile of ten tutors of a private higher education institution in the city of Londrina-PR; to present the perceptions of these tutors about their initial training regarding the use of technologies; to identify if these professionals feel prepared to mediate learning in the Virtual Environment of Teaching and Learning; to know the perception of these tutors about the atmosphere received at the institution when starting their activities in distance education; to verify the difficulties of pedagogical mediation; to
\end{abstract}


check how the tutor performs the student's harvest at a distance; and finally, to analyze if the actions of the tutors contemplate a perspective of humanized education. This theme is relevant, since the role of the tutor is revealed as a facilitator of the teaching-learning process. They were brought to light some thoughts from the theoretical framework of the Schimidt and Marinho (2011), Belloni (2012), Moran (2015) and Gasparoni (2017); as a methodological approach, it was decided by the contributions of Severino (2007); and finally counted on the analysis of interpretations of the data, the light of Schimidt and Marinho perspective (2011), Tenório, Souto and Tenório (2014). The results showed that the respondents have the ability to direct their practices through reception actions and incentives which corroborates the perception of reference on humanized tutoring.

Keywords: Technology. e-learning. Humanization.

\section{El sentido del concepto humanizador en el trabajo de tutores a distancia}

Resumen: Este estudio presenta el perfil de diez tutores de una institución de educación superior particular de la ciudad de Londrina-PR, así como las percepciones de los tutores sobre su formación inicial en relación al uso de tecnologías; identifica si estos profesionales se sienten preparados para mediar el aprendizaje en Ambiente Virtual de Educación y Aprendizaje (AVEA); conoce la percepción de los tutores sobre la ambientación recibida en la institución al iniciar sus actividades en educación a distancia; verifica las dificultades encontradas durante la mediación pedagógica; conoce la forma como el tutor realiza la acogida del alumno a distancia; y, finalmente, analiza si las acciones de los tutores contemplan una perspectiva de educación humanizada. Tal temática es importante, ya que el papel desempeñado por el tutor se revela en cuanto facilitador del proceso enseñanza-aprendizaje. Fueron contempladas algunas reflexiones a partir del aporte teórico de Belloni (2012), Moran (2015) y Gasparoni (2017); en el abordaje metodológico, se opto por las contribuciones de Severino (2007); y, por último, se contó con el análisis de las interpretaciones de datos, a la luz de la perspectiva de Rodrigues, Schimidt y Marinho (2011), Tenório, Souto y Tenório (2014). Los resultados mostraron que los investigados tienen capacidades para orientar sus prácticas por medio de acciones de acogida e incentivo, lo que contribuye para la percepción de los referenciales sobre la tutoría humanizada.

Palabras clave: Tecnología. Educación a distancia. Formación de tutores humanizadores.

\section{Introdução}

Os trabalhos realizados pelos tutores em Ambientes Virtuais de Ensino e Aprendizagem (AVEA) se constituem por estratégias facilitadoras e mediadoras, de modo que os alunos possam ser orientados a fazer uso das ferramentas disponíveis em um espaço de comunicação dialógica de construção ativa e afetiva (ALMEIDA, 2009; SILVA; FIGUEIREDO, 2012). Se o processo de interação entre tutor e aluno for além do papel das relações estabelecidas nesses espaços educativos, com algum grau de afetividade e de cordialidade, possibilitará uma prática inerente aos princípios humanizadores (TENÓRIO; SOUTO; TENÓRIO, 2014; ALMEIDA, 2009). 
O ensino promovido por Tecnologias Digitais de Informação e Comunicação (TDICs) que integram os processos de comunicação na educação a distância $(\mathrm{EaD})$ é a experiência concretizada, oportunizada por um mediador - nesse caso, o tutor -, em um processo de articulação entre a subjetividade dos sujeitos com o meio externo, o que contribui para conferir sentido à experiência de articulação com o conhecimento. Portanto, os significados aferidos à aprendizagem não podem ser simplesmente transmitidos, mas devem ser construídos de forma interativa e afetiva (SILVA; FIGUEIREDO, 2012).

Os conhecimentos articulados na EaD se constroem de forma dinâmica e, apesar de terem sido elaborados com base na perspectiva de um professor-autor, a quem deve ser dado o crédito por desenvolver o material didático a ser disponibilizado na Plataforma, ganham diferentes significados a partir do momento em que o professor-tutor consegue veicular a informação à procura de vários sentidos que outras pessoas, de diferentes concepções e lugares, dão ao conhecimento sua própria existência,

Por ter uma função estratégica e articuladora, esse profissional ganha destaque na área de educação. Nesta pesquisa, tratar-se-á especificamente do papel do tutor a distância, o qual atua diretamente com as disciplinas desenvolvidas com a utilização de recursos tecnológicos, previstas nos cursos presenciais. Assim, das suas atribuições, caberá a de recriar espaços de aprendizagem, tornando o conhecimento em vivência significativo. Nesse sentido, os recursos midiáticos que compõem essa construção, ao serem selecionados, deverão atender ao ideal de construção dinâmica do conhecimento complexo e mediação próprios para a educação a distância, favorecendo diferentes formas de circulação e significação do conhecimento, promovendo a comunicação polissêmica e aprendizagem significativa (MOREIRA; MASINI, 1982) em uma linguagem compatível, como o AVEA.

Especialmente quando se trata das mensagens e dos feedbacks aos alunos, exige-se do tutor maior autonomia, mas não poderão ser vistas como componente meramente formal, e sim representam uma forma complementar de fazer sentido ao material que foi postado na Plataforma. Se os conteúdos apresentados, como qualquer outro tipo de interação prevista (hiperlinks, links e outros objetos de aprendizagem), forem explorados por meio do diálogo, questionamentos e elucidações, o conhecimento se torna uma vivência ativa e participativa (VALENTE, 2014; KENSKI, 2010).

Desse modo, em se tratando de tutoria a distância, suas atribuições adquirem características diferentes das mediações realizadas presencialmente, tanto pela forma quanto pelos estímulos. Assim, as diferentes ferramentas previstas darão subsídios para que esse importante agente possa conduzir seu trabalho de forma interativa e participativa. Entretanto, a escolha dos recursos utilizados exige um olhar diferenciado quanto aos seus distintos usos e possibilidades, por considerar a realidade de cada turma e quais as potencialidades e limitações dos recursos em cada contexto (MORAN, 2015). 
Em relação a isso, caberá a esse profissional, além de atuar como facilitador do processo de ensino e aprendizagem, aprimorar-se a cada dia por meio de cursos de formação continuada, os quais levem a buscar soluções que possam resolver os impasses gerados de ordem didático-pedagógicas, objetivando não só as experiências que os acadêmicos possam construir em sua trajetória formativa, mas elevar ainda mais o nível de interação participativa desses sujeitos.

Portanto, o uso de tecnologias, apropriadas ao contexto educacional e ao público-alvo do curso, deve garantir ao aluno parcela de motivação e subsídios para apropriação dos conhecimentos, originando discussões sobre os principais temas à medida que forem contextualizados, para que esses estudantes construam como transpor as inúmeras complexidades e desafios percebidos na sociedade.

Assim, as ações do tutor ganham destaque, uma vez que é ele o responsável por observar o processo de desenvolvimento dos alunos por intermédio de interações dialógicas e participativas. Um rápido olhar sobre seu papel ajuda a compreender o motivo pelo qual agir com humanização, no contexto do AVEA, passa a ser considerada como atividade relevante. Os alunos que realizam atividades a distância precisam se sentir acolhidos em todo o seu processo de construção ativa e, ainda, sentirem-se desafiados no exercício diário de suas atividades práticas, além de possuírem automotivação para realizar seus estudos, o que pressupõe, até certo ponto, ser possível a partir de uma interação mediada de qualidade, à luz de uma tutoria humanizada.

Sob influência de uma tutoria com base na perspectiva "humanista" (ROGERS, 1997), considera-se que o tutor é o agente responsável pela mobilização do pensamento autônomo, já que, na EaD, a "autoaprendizagem" é um dos critérios imprescindíveis na configuração e estruturação dessa modalidade de ensino (BELLONI, 2012). Esse "caminhar" pode ser o primeiro passo para o entendimento da tutoria humanizada, e um passo maior ainda para o ensino. Como proposta, faz-se necessário sair do papel de agentes passivos para o ato de mediador do conhecimento, o que permite contribuir e enaltecer as conquistas dos alunos. Essa forma de tutoria humanizada motiva os alunos e os incentiva a desenvolver potenciais e a construir conhecimentos.

Nesse sentido, este trabalho tem como objetivos: apresentar o perfil de dez tutores de uma instituição de ensino superior particular da cidade de Londrina, no Paraná; apresentar as percepções desses tutores sobre sua formação inicial no que se refere ao uso de tecnologias; identificar se esses profissionais estão preparados para mediar a aprendizagem em AVEA; conhecer a percepção desses tutores sobre a ambientação recebida na instituição ao iniciar suas atividades no ensino a distância; conhecer as dificuldades encontradas durante a mediação pedagógica; verificar como o tutor realiza a acolhida do aluno a distância; e, por fim, analisar se as ações dos tutores contemplam uma perspectiva de educação humanizada. 
O estudo está dividido em quatro seções: esta primeira apresenta a introdução; a segunda propõe uma discussão a partir de uma revisão de literatura sobre algumas temáticas associadas ao conceito de ensino a distância e humanização; a terceira apresenta as discussões sobre os resultados; e a última, as considerações finais.

\section{$\mathrm{O}$ contexto da $\mathrm{EaD}$ e a prática de tutoria humanizada}

Autores têm se ocupado em entender o contexto da EaD e as condições que se revelam como essenciais para a construção da identidade profissional do tutor, do exercício que os leva a assumir diversos compromissos, do contato direto com o aluno pela Plataforma (DIAS; SILVA, 2016). Entretanto, sua prática docente ainda se configura dentro de inúmeras complexidades e desafios controversos que se revelam diante de uma falta de parâmetro sobre a ausência de uma compreensão clara sobre sua prática (MAROSTI; SILVA; COSTA, 2015).

O avanço tecnológico e, consequentemente, a incorporação de diferentes mídias na educação possibilitaram "contribuir inestimavelmente para a transformação dos métodos de ensino e da organização do trabalho nos sistemas convencionais" (BELLONI, 2012, p. 5). Contudo, é importante discutir os preceitos da EaD, tendo em vista o compromisso assumido e seu papel social perante a sociedade sobre o processo de formação dos sujeitos. Aliados a tais questões, reforça-se ainda a responsabilidade dessa modalidade quanto à qualidade de oferta dos cursos, uma vez que o acesso à educação não significa, entretanto, o (bom) emprego desta, que deveria ser um direito.

São inúmeros os elementos que interferem na construção de um ensino de qualidade, o qual permite inferir que o ponto de partida poderia priorizar a formação continuada daqueles que estão, direta ou indiretamente, envolvidos nos processos de ensino e aprendizagem e dos quais espera-se que não só sejam habilitados na área de conhecimento em que atuam, mas sejam conhecedores dos saberes ali apresentados, que façam relação entre a teoria e a prática e, ao mesmo tempo, que eles próprios os analisem para que possam construir seus próprios pensamentos. Isso significa levar o aluno à construção de um pensamento complexo (MORIN, 2008) que o torne capaz, a partir da compreensão do contexto e dos significados, de construir hipóteses, estabelecer conexões e chegar a resultados.

Todavia, essas necessidades são reforçadas por Freire (2003), que salienta que não há conhecimento válido se não for compartilhado, pois é por meio do diálogo que um conjunto de pessoas legitima uma ideia. Dessa forma, a proposta pedagógica da universidade deverá conceber o ambiente educacional como um espaço aberto à iniciativa, ou seja, o locus de interação, mediação e construção de conhecimentos. 
Essas dimensões indicam a complexidade que permeia a prática da tutoria, uma vez que os desafios inerentes a ela são imensos, e o mediador nem sempre está preparado para enfrentá-los. Para tanto, nem sempre esse sujeito possui a consciência de que a construção de uma sociedade pode se iniciar por meio das ações que acontecem dentro e fora do contexto educativo, nos conhecimentos que apresentam os alunos e que podem incentivá-los a refletir sobre a importância da formação do cidadão, sobre os saberes necessários para atuarem como professores e sobre como fazem e articulam as estratégias previstas na Plataforma.

Por ter um papel tão relevante, no modelo de tutoria adotado pela instituição de ensino superior, essa função é realizada pelo professor-tutor, o qual atua a distância e cuja função é acompanhar todo o processo de desenvolvimento da disciplina, ajudando na construção do plano de ensino, dos conteúdos e das atividades de avaliação. Esse profissional fará toda a mediação do processo de ensino-aprendizagem, estabelecendo conexões entre os conteúdos e os alunos.

Assim, essas são algumas ações que legitimam a necessidade de o tutor elaborar um planejamento diferenciado, a partir do contexto dos seus alunos e das leituras que estes fazem no contexto da EaD. É necessário compreender que formar não é unicamente prover o indivíduo de uma produção de conhecimentos, mas induzi-lo à capacidade de unir, de compreender os acontecimentos que ocorrem durantes as suas práticas, de olhar o outro e a si, de exigir maturidade do aluno sobre sua trajetória formativa e, ao longo desse trajeto, ver-se inserido em um canal de proximidade em meio às condições que se estabelecem entre os envolvidos e, ao conduzi-los nessa direção, assumir as implicações inerentes à sua posição na iminência de uma ação educativa.

São desafios feitos que exigem de seus profissionais preparação necessária para que possam construir/reconstruir suas ideias a partir do trabalho que desenvolvem como mediadores e encarar os duros choques que o contexto da $\mathrm{EaD}$ os impõe, os quais possam ser superados à medida que vivenciam experiências articuladas com a prática. Colocando em prática os saberes que trazem consigo, reconstroem novos conhecimentos ao adquirirem outros saberes ao longo de sua vivência docente, conforme apontado por Tardif (2002) e Gauthier et al. (2006) em suas pesquisas.

Para Gauthier et al. (2006), cada um desses saberes é interpretado e traduzido na ação pelo docente, sendo este dotado de características comportamentais e ideológicas, além da história de vida profissional, concepções acerca do ofício em sala de aula, entre outros aspectos.

Conforme Tardif (2002, p. 230), os professores são considerados "práticos refletidos ou reflexivos" por construírem saberes específicos em relação ao trabalho que desenvolve e por reorganizá-los, aperfeiçoá-los e introduzi-los em sua prática docente. O professor, portanto, não é visto como transmissor de conhecimentos já produzidos, mas como um agente autônomo, que produz saberes e práticas inovadoras, favorecendo a autonomia da aprendizagem e a formação de futuros práticos. 
À luz dessas concepções, articulam-se estratégias sobre a necessidade de desenvolver processos formativos docentes que permitam articular diferentes dimensões, assim como utilizar estratégias pedagógicas participativas e de construção coletiva que favoreçam educar para a humanização.

A esse respeito, Gasparoni (2017), diante da perspectiva humanizadora, afirma que a educação é um ato exercido pelo sujeito, uma habilidade desenvolvida por ele que abarca não só conhecimentos técnicos, mas também comportamentos subjetivos e psicológicos que o levam a refletir sobre sua existência de forma mais profunda, porém mais prática, possibilitando-lhe distinguir, com mais clareza, as causas e seus efeitos e a essência daquilo que se propõe a conhecer.

A concepção humanizadora da educação tem estreitas relações com uma educação popular, a qual desenvolve nos sujeitos condições para a mudança, realizada a partir deles. Tudo isso só pode ocorrer se houver a abertura para um campo de possibilidades propiciadas pelas instituições sociais que possuem como tarefa principal a educação. Nos espaços educativos, iniciativas que fomentem a reflexão, a ação autônoma e criativa, o planejamento e as estratégias mentais estarão no caminho para a concretização de uma educação popular e humanizadora.

Instigar os estudantes a elaborar pesquisas com a finalidade de pensar soluções para problemas é incentivar, sobretudo, a capacidade humana de coexistir na intersubjetividade, em meio às diferenças entre as pessoas e a complexidade de compreender uns aos outros e aprender a viver em harmonia pelo bem de todos (GASPARONI, 2017).

Em consonância com essa posição, tendo em vista a necessidade de resgatar o sentido da humanização na EaD, devem-se estimular propostas com base no uso pleno de direito, conferido a todos os cidadãos. Em outras palavras, no conjunto dos direitos considerados como fundamentais, como o próprio direito à educação, o ensino a distância precisa promover ações que corroboram diferentes formas de circulação e significação do conhecimento ao assumir sua dimensão formativa tão importante na solidificação dos valores que, de maneira histórica, os homens socialmente reproduzem. A educação pode se dar, por exemplo, pela vivência cotidiana, ou ainda:

[...] na medida em que consegue, de fato, efetivar a cidadania plena, desenvolvendo valores, comportamentos, atitudes, construindo conhecimentos que subsidiam a prática da justiça e o comprometimento socioambiental, garantindo, assim, a dignidade humana a todas as pessoas (DIAS; PORTO apud POZZER, 2012, p. 7).

Em suma, a educação varia de acordo com o tipo de sociedade e suas concepções sobre o papel do homem na vida social, ou seja, as propostas pedagógicas devem, acima de tudo, garantir a formação cidadã, com vistas ao alcance de sua legitimidade. 
Com base na perspectiva interdisciplinar, acredita-se em uma proposta metodológica que esteja pautada na integração dos conhecimentos, que se articule e estabeleça conexões, visando atingir níveis cada vez mais avançados sobre os processos de construção desses saberes.

Tal concepção é amplamente fortalecida pela denominação encontrada em Nicolescu (1999), o qual diz que interdisciplinaridade se refere ao que vai além do campo disciplinar, que atravessa as diferentes linguagens e proposições curriculares. Desse modo, a EaD possibilitará, por meio do modo pelo qual organiza os conhecimentos e a partir dos pontos fundamentais que se encontram em cada área do saber prevista em cada disciplina, identificar em que momento se alinham ou se complementam. Isso significa o que Morin (2008) chama de um "pensamento organizador", o qual atravessa as disciplinas, dando uma espécie de unidade e construindo uma noção de totalidade.

Afora esse quadro das possibilidades do uso das TDIC na educação, pretende-se, a partir dessas considerações, o implemento de uma proposta pedagógica que promova interações mais humanizadas. Logo, a interação entre os indivíduos com o mundo circundante se dá de maneira peculiar, segundo a ação que exercem para transformar, criando e recriando um mundo humano.

\section{Perspectiva humanista na EaD à luz da teoria significativa}

A construção do conhecimento, por meio da interação entre os pares, é requisito básico de uma proposta pedagógica a qual considera um aluno como o centro do processo. Rogers (1997), ao propor a autonomia do aluno, considera o homem como um ser dotado de racionalidade; portanto, livre e com capacidade de trilhar seu próprio caminho.

Nesse sentido, Rogers (1997), importante psicólogo norte-americano, preconizou um modelo de ensino centrado no estudante. Para tanto, mostra-se necessário dizer que não seria possível ensinar diretamente outra pessoa, mas apenas criar condições para que ela se aproprie do conhecimento. Em outras palavras, aprender por si mesmo em uma perspectiva humanista, por analogia, permite considerar que o tutor a distância possa atuar como agente facilitador da aprendizagem, de modo a permitir que o aluno estabeleça relações significativas com o objeto do conhecimento, possíveis por um "relacionamento pessoal entre o facilitador e o aprendiz” (ROGERS; ROSENBERG, 1977, p. 138).

Aponta-se, desse modo, que os conhecimentos ensinados devem relacionar-se com a vida do indivíduo. Nessa perspectiva, considera-se que o ensino possa se efetivar com o apoio das ferramentas tecnológicas, desde que aliada à comunicação afetiva para "aprender a partir das histórias de vida e dos sonhos de cada um dos alunos" (MORAN, 2015, p. 33). 
O texto de Moran (2015) traz importantes apontamentos sobre como o ensino deve se efetivar em uma proposta pedagógica, na qual seja possível discutir os interesses aliados às necessidades dos alunos a partir de recursos mediáticos que veiculem diferentes formas de circulação e significação do conhecimento, ao promover a comunicação dialógica e a aprendizagem significativa (MOREIRA; MASINI, 1982).

Nesse debate, considera-se que a própria pessoa possa atribuir significado ao conhecimento. Em uma visão dialógica, isso permite diminuir a distância entre aquilo que se sabe e aquilo que se compreende, integrando conhecimento e atitudes do dia a dia.

Assim, os conhecimentos científicos, resultados dos saberes acumulados pelas gerações, possíveis pelo uso das TDIC, sobretudo associadas ao uso da internet, propiciam diferentes respostas e novas possibilidades de adequações didáticas em meio à facilidade de oferecer novas oportunidades para o aprendizado. Contudo, conforme nos aponta Valente (2014, p. 142), é possível perceber nitidamente que o uso dessas tecnologias se efetiva mais facilmente na área comunicacional do que na educação, pois "esta ainda não incorporou e não se apropriou dos recursos oferecidos pelas TDICs".

Para tanto, entender as relações que se configuram nos espaços interativos da aprendizagem digital implicaria, de certo modo, analisar o contexto dessas novas configurações, por meio de um novo patamar:

A ação educacional consiste justamente em auxiliar o aprendiz, de modo que a construção de conhecimento possa acontecer. Isso implica criar ambientes de aprendizagem onde haja tantos aspectos da transmissão da informação quanto de construção, no sentido da significação ou da apropriação da informação (VALENTE, 2014, p. 144).

Nessa concepção, sugere-se que tanto tutores quanto os alunos, responsáveis pelo processo de ensino e aprendizagem, utilizarão do conhecimento científico ao aplicá-lo por meio do trabalho em equipe, pesquisas, estudos de caso, resolução de problemas relativamente complexos, e, assim, entender e usufruir das potencialidades tecnológicas do mundo que os cerca.

De modo geral, a função de tutoria merece destaque, sobretudo com relação à proximidade que estabelece com os alunos, pois, ao assumir a função de mediador do conhecimento, o tutor os conduz à prática da vida social, o que vai muito além do seu papel social institucional de prepará-los para o mundo do trabalho.

A educação na atualidade, portanto, apresenta-se como um ambiente propício ao se revelar potencialmente articuladora de combate à própria estrutura social contemporânea, marcada pela impessoalidade e superficialidade. Nesses ambientes, os tutores poderão ser instrumentalizados por intermédio dos estu- 
dos sobre os direitos humanos, os quais poderão lhes fornecer, enquanto subsídios, princípios norteadores que regem os conceitos de cidadania e humanização do ensino. Por conseguinte, poderão articular estratégias de aprendizagem que possibilitem refletir de maneira plena o papel dos cidadãos e suas relações políticas, culturais e econômicas, uma vez que os conceitos de Educação em Direitos Humanos $(\mathrm{EDH})$ sobre o uso de direitos sociais não ocorrem de forma espontânea, mas efetivam-se por meio de proposta pedagógica articulada com uma concepção humanista, a partir da assertiva presente no caput do art. $5^{\circ}$, da Resolução nº 1 (BRASIL, 2012):

A Educação em Direitos Humanos pode ser definida como um conjunto de atividades de educação, capacitação e de difusão de informação, orientada para a criação de uma cultura universal de direitos humanos.

Nessa perspectiva, corroboram-se princípios teórico-metodológicos que compreendem o modo de conduzir o uso das tecnologias. Para Freire (2003), entender o processo é de suma importância, visto que conduz os homens à "humanização". Freire (2003) busca compreender não só a realidade como também se dedica a certa proposição reconstrutiva da realidade, por meio de uma argumentação crítica "quando se diz ao educador como fazer tecnicamente uma mesa e não se discute as dimensões estéticas de como fazê-la, castra-se a capacidade de ele conhecer a curiosidade epistemológica" (FREIRE; PASSETTI, 1994-1995, p. 87).

Consequentemente, apresenta-se a necessidade de que o tutor possa revisitar o seu papel continuamente, pois, além de apropriar-se do modelo educacional, da proposta pedagógica da instituição, deverá, portanto, dominar com êxito o uso das ferramentas disponíveis na plataforma, assim como apresentar um perfil que permita estabelecer relações de empatia com o aluno (TENÓRIO; SOUTO; TENÓRIO, 2014) e, ao mesmo tempo, possibilitar o desenvolvimento de ações sob o enfoque da tutoria humanizada e humanizadora, com vistas ao alcance de uma visão global da educação enquanto prática humana transformadora.

\section{Procedimentos metodológicos}

Esta pesquisa caracteriza-se, basicamente, como bibliográfica, de campo e analítica. Ela é de campo porque se desenvolveu o estudo com dez tutores de cursos a distância de uma instituição particular localizada ao norte do Paraná (GONSALVES, 2001). A modalidade bibliográfica efetivou-se pelas consultas a publicações impressas e eletrônicas referentes, sobretudo, ao tema $\mathrm{EaD}$ e tutoria humanizada, foco da pesquisa empreendida (MARCONI; LAKATOS, 1992). A interpretação dos resultados evidenciou a natureza analítica do estudo (SEVERINO, 2007). 
O instrumento de coleta de dados a ser aplicado aos participantes da investigação foi elaborado por meio da ferramenta Google Docs. Ele é composto por sete questões: de 1 a 4, objetivas, e de 5 a 7, subjetivas. As questões buscavam identificar o perfil dos tutores, suas percepções sobre a própria formação e prática, sobre a ambientação que eles receberam ao iniciar as atividades na instituição na qual atuam, sobre as dificuldades enfrentadas na mediação pedagógica e sobre os desafios presentes na EaD.

O questionário foi encaminhado a 16 tutores, os quais possuem formações de acordo com o curso que atendem; no entanto, trata-se apenas de disciplinas ofertadas a distância, previstas nos cursos de graduação presencial, por meio de recursos tecnológicos. Suas formações correspondem às seguintes áreas: Enfermagem (dois), Pedagogia (dois), Direito (dois), Administração (dois), Fisioterapia, Medicina Veterinária, Arquitetura, Ciências da Informação, Engenharia, Ciências Contábeis, Teologia e Agronomia. Os pesquisados foram escolhidos de forma aleatória, mas exercem com maestria atividades de planejamento com a equipe pedagógica.

Dos 16 questionários enviados, apenas sete foram respondidos no prazo estabelecido (após o recebimento, tiveram o prazo de uma semana para respondê-lo); entretanto, após nova tentativa, com prazo de mais cinco dias, três novos questionários retornaram. Assim, a coleta de dados contou com um prazo de duas semanas para ser concluída e com a participação de dez participantes, os quais serão representados pelas identificações: (T1), (T2), (T3), (T4), (T5), (T6), (T7), (T8), (T9) e (T10).

\section{Resultados e discussão}

Dos tutores pesquisados, apenas um (10\% dos pesquisados) tinha concluído recentemente a graduação e cursava especialização na área de educação, sete $(70 \%)$ eram especialistas e dois (20\%) eram mestres e cursavam o programa de doutoramento. Tal constatação indica que esses profissionais estão em busca de capacitação e recorrem, geralmente, à formação continuada por meio de seus ingressos em programas de pós-graduação stricto e lato sensu.

Os resultados mostraram que, com exceção de um dos participantes, os demais $(90 \%)$ graduaram-se há, aproximadamente, 15 anos, no entanto, em consulta aos seus históricos acadêmicos, apenas na licenciatura em Pedagogia identificou-se disciplina relacionada ao uso de tecnologias. Os demais informantes tiveram contato com o uso das tecnologias em cursos de especialização.

Logo no primeiro questionamento "Você se considera preparado (a) para realizar o trabalho de mediação e acompanhamento da aprendizagem, por meio do AVEA (Ambiente Virtual de Ensino e Aprendizagem)?”, os dez participantes responderam que "sim". Esse fato representa que a formação continuada dos 
tutores deu a eles confiança para o uso das TDICs no que se refere ao trabalho desenvolvido na tutoria. Seja a formação inicial, seja a continuada, a competência e confiança são fundamentais para o trabalho de mediação com o uso dos recursos midiáticos.

Todavia, essas referências não são atribuídas à formação que recebem ao iniciarem suas atividades na $\mathrm{EaD}$, evidentes a partir do segundo questionamento, "Ao realizar suas atividades em tutoria, participou de algum tipo de formação?", questão à qual todos (100\%) responderam "não participei”. Essas respostas evidenciaram a percepção que os tutores apresentam sobre a "ambientação" como proposta de formação continuada prevista no programa de formação docente da instituição, a qual propõe, no cerne de sua constituição, ao menos no plano teórico, um delineamento sobre a atuação do tutor, realizada de forma presencial, em que se apresentam discussões sobre as principais teorias que abordam os processos teóricos e metodológicos na EaD.

No entanto, tal formação recebida, acrescida dos desafios que se colocam quanto ao exercício de suas funções em tutoria, na opinião dos participantes não se efetivava enquanto recurso facilitador sob o ponto de vista pedagógico, uma vez que não a relacionavam com "formação".

A partir das respostas, e tendo em vista o enfoque institucional de que a formação continuada seja constituída como ação docente instrumentalizada pela reflexão, investigação e construção de novos saberes, que (re)orientam o trabalho docente, é imprescindível que a instituição na qual atuam os tutores reelabore nova proposta de criação de um curso de formação que possa fornecer e viabilizar ferramentas necessárias para instrumentalizar os tutores no uso de suas atividades diárias em AVEA.

A terceira pergunta foi: "Quais estratégias são utilizadas para acompanhamento das atividades realizadas pelos alunos no AVEA?’. Assim, procurou-se compreender como eram realizados os acompanhamentos com efeito de validação sobre os processos construídos a partir das evidências sobre o nível de aproveitamento dos alunos nas atividades. A pesquisa revelou que o monitoramento sobre as participações nas atividades acontecia por meio de recursos que mensuravam, por meio de gráficos e tabelas, os resultados obtidos.

Apesar de os dados demonstrarem que 100\% dos tutores utilizavam esses instrumentos, ficando evidente seus benefícios, preocupava-os, contudo, a sensação de falta de entendimento pleno sobre o que necessitava ser melhorado, uma vez que tais recursos não conseguiam avaliar em "profundidade" todos os aspectos observáveis, com vistas ao atendimento da aprendizagem significativa.

Desse modo, identificar possíveis "falhas" no processo de construção da aprendizagem passa ser tarefa primordial. Além das respostas constituírem-se em exemplos - tais como "disparos eletrônicos, com pessoalidade", "feedbacks individuais, seguidos de elogios e incentivos", e até "contato via telefone" -, sua 
ação é meramente técnica sob o ponto de vista operacional, por não lhes assegurar o nível de entendimento necessário exigido na elaboração e reconstrução do conhecimento por parte dos acadêmicos.

Diante da necessidade de criar condição de aproximação e melhorias sobre os resultados do processo de ensino aprendizagem, as universidades, segundo Belloni (2012), sobretudo no início, davam ênfase a esse tipo de recurso por se constituir como "meios técnicos para aumentar a eficácia do sistema". Entretanto, esses mecanismos aportam a um modelo de educação centrado no ensino, e não no aprendente, conforme nos aponta a autora:

[...] nota-se uma ênfase excessiva nos processos de ensino (estrutura organizacional, planejamento, concepção de metodologias, produção de materiais etc.) e pouca ou nenhuma consideração dos processos de aprendizagem (características ou necessidades dos estudantes, modelos e condições dos estudos, níveis de motivação etc.) (BELLONI, 2012, p. 30, grifos do autor).

Não obstante, esses recursos por si só não conseguem mensurar o nível de proficiência necessária a ser atingido pelo estudante, o que pressupõe que eles precisam ser validados com as demais avaliações previstas, de modo a coletar evidências significativas e a fornecer aos alunos e educadores elementos necessários para a tomada de decisão quanto à melhoria do processo ensino e aprendizagem.

A quarta questão tratou das dificuldades que os tutores enfrentavam em seu dia a dia; os resultados mostraram que, apesar de os alunos viverem no espantoso avanço das TDICs, na percepção de três tutores (30\% das respostas), os alunos não se sentiam seguros quanto ao uso dessa ferramenta para fins educativos, o que permite desmistificar como esses tutores veem o uso de tecnologias para mediação do conhecimento, uma vez que, ao serem questionados "Qual é a maior dificuldade que enfrenta no dia a dia com relação às atividades que exerce em tutoria?", relativa às atividades que exercem em tutoria, relataram:

(T1) Um pouco de preconceito dos alunos em relação à modalidade de ensino a distância.

(T3) Dificuldade de proporcionar uma interação entre os próprios alunos.

(T10) As dificuldades são muitas, desde a falta de interesse até o acompanhamento da aprendizagem.

A esse respeito, Valente (2014, p. 144) alerta que:

[...] a questão fundamental no processo educacional é saber como prover a informação, de modo que ela possa ser interpretada pelo aprendiz que passa a entender quais ações ele deve realizar para 
que a informação seja convertida em conhecimento [...]. Porém, se tais tecnologias não forem compreendidas com um foco educacional, não será, simplesmente, o seu uso que irá auxiliar o aprendiz na construção do conhecimento.

Apesar de os demais entrevistados relatarem não encontrar dificuldades relacionadas ao uso da ferramenta, o que pressupõe lidarem de forma segura com a possibilidade de mediação por meio de uma ferramenta tecnológica, ressalta-se, novamente, a importância em se promoverem ações, nos programas de capacitação, destinadas tanto ao corpo docente quanto à equipe técnica, para que possam auxiliar e dar suporte aos alunos na utilização das mais diversas tecnologias e ferramentas, bem como oferecer cursos de ambientação para que o aluno conheça e interaja com os recursos disponibilizados.

A quinta questão foi: "Quando o aluno apresenta dúvidas, como você procura resolvê-las?". Aponta-se, desse modo, sobre o modo de lidar com as dificuldades, o que demonstra preocupação com os estudantes. Além de acompanhar as atividades curriculares, eles tentam motivá-los a aprender, orientam e proporcionam aos alunos condições de uma aprendizagem autônoma, atendendo ao que apregoa a tutoria humanizada:

(T1) Primeiramente buscamos individualizar quem é o aluno, pois cada um deles possui suas particularidades, e sempre tentamos trabalhar com uma linguagem que esteja mais próxima dos nossos alunos. Após superada essa primeira etapa, busca-se através da Plataforma orientar o aluno na concepção da atividade. Caso seja constatado que o aluno ainda encontra dificuldades, buscamos um encontro presencial com o próprio aluno e na impossibilidade fazemos um contato telefônico.

(T7) [...] estou enviando alguns materiais de apoio e um tutorial com exemplos a respeito de suas dificuldades e apontamentos para que você possa esclarecer e compreender melhor esse assunto ou disciplinas [...].

Rodrigues, Schimidt e Marinho (2011) afirmam que o tutor é uma figura estratégica nos cursos a distância - é o agente responsável por orientar, guiar, provocar, instigar o aluno, despertando-lhe o interesse pelo curso, o desejo de aprender e de buscar novos horizontes. Ele participa ativamente do processo de ensino-aprendizagem e contribui para o acompanhamento e avaliação do projeto pedagógico.

A sexta questão foi: "Ao perceber que o seu aluno está ausente e essa condição pode refletir em seu desempenho, o que você faz?". Tendo como princípio da EaD a mediação pelo uso de tecnologias, a ausência do aluno, sob o ponto de vista pedagógico, pode evidenciar desde desmotivação e falta de interesse até dificuldade para lidar com a situação de aprendizagem. 
Assim, 70\% das respostas dos entrevistados revelaram-se efetivamente baseadas em uma perspectiva humanizada, na qual se pressupõem relações de acolhida e de acompanhamento individualizado:

(T1) Primeiramente envio uma mensagem de incentivo via (mensagens do curso). Caso não surtir um efeito, envio uma mensagem de incentivo e perguntando o porquê de sua ausência e dificuldade (para seu e-mail particular).

(T2) Estou entrando em contato para lembrá-lo sobre o exercício liberado nessa semana. Não deixe de fazê-lo, pois sua participação é muito importante, além de você poder avaliar os seus conhecimentos, ela poderá auxiliá-lo a esclarecer outros conceitos ou ainda utilizar desses conhecimentos no futuro. Qualquer dificuldade, não hesite, estou sempre à disposição.

(T7) Os alunos se mostram ausentes, no meu ponto de vista, quando respondem sem critérios, ou seja, às vezes participam para "cumprir tabela". Essa ausência é relativa, pois, às vezes, o simples acesso não significa que está participando de fato.

(T10) Analiso as respostas para saber se houve algum tipo de construção, no entanto a ausência naquela resposta não diz respeito ao processo como um todo. Precisamos acompanhá-lo e conhecê-los e a ausência pode ser sinônimo de dificuldade.

Apesar do acesso demonstrado por meio dos diferentes canais de comunicação disponíveis no AVEA (mensagens, notificações, e-mails etc.), demonstrados na fala de (T1), os tutores, quando muito, procuram esses respaldos de aporte técnico-prático fundamentados na utilização dessas ferramentas para tentar amenizar a situação - nesse caso, a ausência do aluno. Contudo, dado o fato de que alguns alunos ainda mantêm um comportamento ausente, considera-se que eles possam repensar suas práticas para transformação dessa realidade, o que foi possível de identificar nas falas dos tutores (T7 e T10).

Logo, Tenório, Souto e Tenório (2014) afirmam que, para os profissionais exercerem suas funções na $\mathrm{EaD}$, não basta empregar métodos modernos e tecnologias avançadas. A concretização do processo de ensino e aprendizagem a distância necessita de outras habilidades, como as competências socioafetivas. O tutor a distância, educador com atuação muito próxima ao aluno, deve ser capaz de estimular os alunos de um curso de EaD por uma comunicação cordial, prazerosa e instigante, deixando-os mais confortáveis e seguros para a interação com todo o grupo. Nesse contexto, a competência socioafetiva é a cordialidade, atribuída à fala na resposta (T2), o que demonstra a habilidade de estabelecer relações de empatia com o aluno.

$\mathrm{Na}$ sétima e última questão, a pesquisa demonstrou a importância de se trabalhar a construção/reconstrução das ideias dos tutores sobre seu trabalho enquanto profissionais, com base em uma perspectiva humanizada. Assim, por 
meio das respostas, buscou-se analisar algumas implicações relacionadas às próprias limitações e ao papel do mediador a partir da perspectiva da humanização, uma vez que ele se interpõe entre o sujeito e o objeto do conhecimento.

Isso posto, por meio de suas ações, é possível organizar, selecionar, interpretar e elaborar aquilo que foi experimentado, de acordo com as necessidades do sujeito mediado. A pergunta proposta foi: "Como realiza a acolhida aos alunos, utilizando-se, nesse caso, das ferramentas disponíveis? Relate aqui sua experiência sobre o assunto". Serão apresentados excertos de fala de alguns dos participantes da pesquisa:

(T1) Sempre iniciamos com uma mensagem pessoal, pois acreditamos que o aluno se sinta acolhido e especial, pois sempre que enviamos mensagens para todos se torna uma comunicação muito distante.

(T4) Dou as boas-vindas, falo quem sou, que estou à disposição para auxiliar nas dúvidas. Informo meu dia de permanência na instituição e telefone.

(T8) Procuro me apresentar, dizer quem sou, minha experiência na área. Após, peço que ele se apresente também e nessa apresentação, dou um feedback positivo, do tipo, "que bom estarmos juntos, tenho certeza que nossos estudos serão muito produtivos".

(T10) Seja bem-vindo ao curso... nele você vai encontrar muita interatividade. Nosso contato será pela Plataforma de estudos, porém fique à vontade para entrar em contato no meu dia de permanência na instituição.

Em tais excertos, fica evidente a preocupação por parte dos pesquisados em criar um clima favorável para a aprendizagem, por meio de incentivos, com vistas a ajudar o aluno a buscar diferentes formas para que se concretize o aprendizado. A abertura para o contato "telefônico", identificada nas respostas (T4 e T10), revela-se uma possibilidade a mais em colocar-se à disposição e ajudá-los a enfrentar as dificuldades vivenciadas em seu dia a dia.

Observa-se que, com base na proposta metodológica adotada pela instituição em estudo, via de regra, a relação estabelecida entre tutor e aluno deveria ser estabelecida por meio das ferramentas disponíveis alocadas na Plataforma. Entretanto, caberá ao tutor a distância identificar até que ponto somente o contato a distância é passível de esclarecer e sanar todas as dúvidas dos alunos.

Assim, nem sempre é possível conferir resultados positivos diante desses aspectos. Confirmando Tardif (2002), a prática docente não se restringe a um espaço de entrega dos saberes - nesse sentido, dos conteúdos -, mas compreender que essa prática é também o local do seu fazer pedagógico, que vai além de "transmitir" conhecimentos, é conhecer seus alunos e seu ritmos, é saber avaliar cada um com suas limitações; portanto, é interagir de forma abrangente e transpor os desafios intrínsecos específicos do contexto da EaD. 


\section{Considerações finais}

Este estudo buscou refletir sobre o trabalho realizado por tutores em $\mathrm{EaD}$ a partir do enfoque da educação humanizada. Entende-se que a promoção de uma tutoria humanizada parte, necessariamente, de programas de formação continuada, mas ligada diretamente às características de personalidade dos seus agentes. Entre os esforços evidenciados que nortearam os resultados positivos, a partir da análise das respostas dos tutores, identificaram-se: a busca desses profissionais por formação continuada, lato e stricto sensu (apenas um dos tutores teve em sua formação inicial contato com o uso de tecnologias); a ambientação recebida na instituição se concretiza por meio de discussões sobre as principais teorias que abordam os processos teóricos e metodológicos na EaD. No entanto, os participantes não consideram esses encontros como momentos de formação.

Além disso, os tutores avaliam os resultados obtidos pelos alunos por meio de gráficos e tabelas, contudo entendem que tais recursos não conseguem avaliar com "profundidade" todos os aspectos observáveis. Sobre as dificuldades enfrentadas com os alunos que realizam disciplinas a distância, os participantes destacaram que estes não se sentem seguros quanto ao uso dessa ferramenta para fins educativos. Esse tipo de afirmação denota, para Souza (2006 apud MELO; FIGUEIREDO, 2012, p. 7), que tal situação "reside no receio de que a falta de interação entre os indivíduos dificulte a formação das competências necessárias". Para tanto, reforça a necessidade de criar condições para que os envolvidos possam estabelecer relações de confiança, possíveis por meio de mecanismos como "tutoriais" que facilitem a navegabilidade da Plataforma, além de fornecerem instrumentos para que os alunos possam compreender seu papel, tendo em vista o alcance dos objetivos propostos previstos nas disciplinas, a partir das responsabilidades assumidas diante próprio aprendizado, o que ajuda a reduzir o estresse e a ansiedade dos discentes.

No que se refere à mediação sob uma perspectiva humanizada, os excertos de fala mostram preocupação dos tutores em proporcionar um clima favorável para a aprendizagem, por meio de incentivos, com vistas a ajudar o aluno a buscar diferentes formas para que se concretize o aprendizado.

Assim, verificou-se que os papéis desempenhados por esses tutores são de fato concretizados em ambientes de acolhida e respeito às individualidades de cada sujeito, inseridos dentro de um contexto de diversidade cultural, o que pode ser tomado como um importante passo para além de um discurso vazio, portanto consolidado sob a narrativa comum, de direitos consolidados.

Por meio desse aporte prático, ficou evidente na pesquisa realizada com dez tutores que, na elaboração de suas atividades diárias, os tutores se deparam com diversos desafios e problemas inerentes à sua rotina. Todavia, tais situações, 
pertinentes a qualquer profissão, não podem se revelar como inviabilizadoras, pois poderão ser superadas por meio de programas de formação continuada, com propostas de formação cidadã, com vistas ao alcance de sua legitimidade, sem, contudo, restringi-las somente ao plano filosófico.

Portanto, entende-se ser possível, na modalidade EaD, a promoção de espaços para aprendizagem entre alunos e tutores, de modo a fortalecer os diálogos sobre a prática pedagógica desses profissionais, contribuindo com o seu aprimoramento constante. Para isso, as atividades deverão ser elaboradas e acompanhadas por uma educação humanizadora, o que ocorrerá, até certo ponto, com uma tutoria humanizada.

Recebido: $10 / 09 / 2017$

Revisado pelo autor: 16/10/2017 Aceito para publicação: 25/10/2017

\section{Notas}

1 Mestranda no Programa de Pós-Graduação em Ensino de Ciências Humanas, Sociais e da Natureza (PPGEN) da Universidade Tecnológica Federal do Paraná (UTFPR), campus Londrina, (2016). Especialização em Docência para a Educação Profissional (2011/2012). Especialização em Metodologia da Ação Docente (2009/2010). Especialização em Psicopedagogia Clínica e Institucional (2004/2005). Graduação em Pedagogia (2004). Supervisora acadêmica em Centro Universitário Filadélfia (UniFil). E-mail: cleo_martinsfranca@hotmail.com.

2 Mestrado pelo Programa de Pós-Graduação em Ensino de Ciências Humanas, Sociais e da Natureza (PPGEN) da Universidade Tecnológica Federal do Paraná (UTFPR), campus Londrina. Especialização em Educação a Distância e graduação em Zootecnia pelas Faculdades Gammon (1996), com Habilitação em Química pela Resolução CNE 02/97. Graduação em Pedagogia pela Universidade Paulista (UNIP) (2015). Tutora presencial dos cursos de Pedagogia e Matemática pela Universidade Virtual do Estado de São Paulo (UNIVESP). E-mail: quimartini@hotmail.com.

3 Doutorado em Linguística e Língua Portuguesa pela Universidade Estadual Paulista (UNESP) (2008). Mestrado em Estudos da Linguagem (2003) e graduação em Letras pela Universidade Estadual de Londrina (UEL). Docente do Programa de Pós-Graduação em Ensino de Ciências Humanas, Sociais e da Natureza (PPGEN) da Universidade Tecnológica Federal do Paraná (UTFPR), campus Londrina. E-mail: alessandradutra@utfpr.edu.br.

4 Doutorado em Ciência Política pela Universidade Estadual de Campinas (UNICAMP) (2013). Mestrado em Educação pela UNICAMP (2006). Mestrado em Geografia Humana pela Universidade de São Paulo (USP) (2002). Docente na Universidade Tecnológica Federal do Paraná (UTFPR), campus Londrina, e do Programa de Pós-Graduação em Ensino de Ciências Humanas, Sociais e da Natureza (PPGEN) da UTFPR. E-mail: davidpereira@utfpr.edu.br.

5 Doutorado em Engenharia pela Universidade de São Paulo (USP) (2010). Mestrado em Administração pela Universidade Federal do Paraná (UFPR) (2003). Graduação em Administração de empresas na FAFICO, atual Universidade do Norte do Estado do Paraná (UENP) (1992). Docente na Universidade Tecnológica Federal do Paraná (UTFPR), campus Londrina, e do Programa de Pós-Graduação em Ensino de Ciências Humanas, Sociais e da Natureza (PPGEN) da UTFPR. E-mail: jair@utfpr.edu.br. 


\section{Referências}

ALMEIDA, Maria das Graças Marinho de. Educação a distância e formação humana: um encontro possível e desejável. Debates sobre Educação, v. 1, n. 1, jan./jun. 2009.

BELLONI, Maria Luiza. Educação a distância. 6. ed. Campinas: Autores Associados, 2012.

BRASIL. Resolução n ${ }^{\circ}$ 1, de 30 maio de 2012. Estabelece Diretrizes Curriculares Nacionais da Educação em Direitos Humanos. Diário Oficial [da] União, Brasília, DF, 31 mai. 2012. Seção 1, p. 48.

DIAS, Francisca Auderlânia de Oliveira; SILVA, Adriana Maria. O uso das ferramentas na educação a distância e o papel do tutor. Id on Line Rev. Psic., v. 10, n. 30 (Supl. 3), p. 16-33, jul. 2016.

FREIRE, Paulo. Pedagogia da autonomia: saberes necessários à prática educativa. 7. ed. São Paulo: Paz e Terra, 2003.

FREIRE, Paulo; PASSETTI, Edson. Conversação libertária com Paulo Freire. São Paulo: Imaginário, 1994-1995.

GASPARONI, Caroline Lisian. Aprendizagem por projetos e iniciação científica a uma educação popular e humanizadora. Revista Retratos da Escola, Brasília, v. 11, n. 20, p. 265-275, jan./jun. 2017. Disponível em: <http://retratosdaescola. emnuvens.com.br/rde/article/viewFile/538/pdf>. Acesso em: 21 ago. 2017.

GAUTHIER, Clemont et al. Por uma teoria da pedagogia: pesquisas contemporâneas sobre o saber docente. 2. ed. Ijuí: Unijuí, 2006.

GONSALVES, Elisa Pereira. Conversas sobre iniciação à pesquisa científica. Campinas: Alínea, 2001.

KENSKI, Vani Moreira. Tecnologias e ensino presencial e a distância. Campinas: Papirus, 2010.

MARCONI, Marina de Andrade; LAKATOS, Eva Maria. Metodologia do trabalho científico. 4.ed. São Paulo: Atlas, 1992.

MAROSTI, Márcio Ricardo Dias; SILVA, Helen Camila da Silva; COSTA, Maria Luisa Furlan. O tutor na EaD brasileira: algumas reflexões. In: CONGRESSO BRASILEIRO DE ENSINO SUPERIOR A DISTÂNCIA, 11., 2014, Florianópolis. Anais... Florianópolis-SC: NUTE-UFSC, 2014. p. 1018-1028.

MORAN, José. Educação híbrida: um conceito-chave para a educação, hoje. In: BACICH, Lilian; TANZI NETO, Adolfo; TREVISANI, Fernando de Mello (Orgs.). Ensino híbrido: personalização e tecnologia na educação. Porto Alegre: Penso, 2015. p. 23-45. 
MOREIRA, Marco Antonio; MASINI, Elcie Salzano. Aprendizagem significativa: a teoria de David Ausubel. São Paulo: Editora Moraes, 1982.

MORIN, Edgar. Os sete saberes necessários à educação do futuro. Brasília: UNESCO; São Paulo: Cortez Editora, 2008.

NICOLESCU, Basarab. O manifesto da transdisciplinariedade. 3. ed. São Paulo: Triom, 1999. Disponível em: <http:// http://ruipaz.pro.br/textos_pos/ manifesto_transdisciplinaridade.pdf $>$. Acesso em: 12 maio 2017.

POZZER, Adecir. A formação de professores em e para direitos humanos: desafios frente à filosofia de Lévinas. In: SEMINÁRIO DE PESQUISA EM EDUCAÇÃO DA REGIÃO SUL, 9., 2012, Caxias do Sul. Anais... Caxias do Sul: UCS/ANPED, 2012. Disponível em: <http://www.ucs.br/etc/conferencias/index.php/anpedsul/9anpedsul/paper/viewFile/337/857>. Acesso em: 17 out. 2017.

ROGERS, Carl. Tornar-se pessoa. 5. ed. São Paulo: Martins Fontes, 1997.

ROGERS, Carl; ROSENBERG, Rachel. A pessoa como centro. São Paulo: EPU/EDUSP, 1977.

RODRIGUES, Cleide Aparecida; SCHMIDT, Leide; MARINHO, Hermínia. Tutoria em educação a distância. Ponta Grossa: UEPG/Nutead, 2011.

SEVERINO, Antonio Joaquim. Metodologia do trabalho científico. 23. ed. rev. e atual. São Paulo: Cortez, 2007.

SILVA, Camila Gonçalves; FIGUEIREDO, Vítor Fonseca. Ambiente virtual de aprendizagem: comunicação, interação e afetividade na EaD. Revista Aprendizagem em EAD, Taguatinga-DF, v. 1, out. 2012. Disponível em: < https:// portalrevistas.ucb.br/index.php/raead/article/view/3254/2229>. Acesso em: 17 out. 2017.

TARDIF, Maurice. Saberes docente e formação profissional. Petrópolis: Vozes, 2002.

TENÓRIO, André; SOUTO, Elizete; TENÓRIO, Thaís. Percepções sobre a competência socioafetiva de cordialidade e a humanização da tutoria a distância. EAD em Foco, Revista Científica em Educação a Distância, Rio de Janeiro, v. 4, n. 1, p. 36-47, 2014. Disponível em: < http://eademfoco.cecierj.edu.br/index. php/Revista/article/view/199/48>. Acesso em: 17 out. 2017.

VALENTE, José Armando. A comunicação e a educação baseada no uso das tecnologias digitais de informação em comunicação. Revista UNIFESO - Humanas e Sociais, v. 1, n. 1, p. 141-166, 2014. Disponível em: <http://www.smeduquedecaxias.ri.gov.br/portal/ead/svp/pluginfile.php/3461/mod_resource/ content/1/valente.pdf >. Acesso em: 10 mai. 2017. 